\title{
Knowledge and Behavior in Rational Drug Use Among College Students in Zunyi City
}

\author{
Chengchen Yin ${ }^{1-3}$, Xing $\mathrm{He}^{1-3}$, Kaili Shen ${ }^{1-3}$, Xingrui $\mathrm{Mu}^{1-3}$, Fushan Tang $\mathbb{D}^{1-3}$ \\ 'Department of Clinical Pharmacy, Key Laboratory of Basic Pharmacology of Guizhou Province and School of Pharmacy, Zunyi Medical University, \\ Zunyi, 563006, People's Republic of China; ${ }^{2}$ Key Laboratory of Basic Pharmacology of Ministry of Education and Joint International Research \\ Laboratory of Ethnomedicine of Ministry of Education, Zunyi Medical University, Zunyi, 563006, People's Republic of China; ${ }^{3}$ Key Laboratory of \\ Clinical Pharmacy in Zunyi City, Zunyi Medical University, Zunyi, 563006, People's Republic of China
}

Correspondence: Fushan Tang, Department of Clinical Pharmacy, Key Laboratory of Basic Pharmacology of Guizhou Province and School of Pharmacy, Zunyi Medical University, Zunyi, 563006, People's Republic of China, Tel +86 85I 2864 2337, Fax +86 85I 2864 2334, Email fstang@vip.l63.com

Objective: To investigate the current status of knowledge and behavior about rational drug use in college students in different colleges and universities in a city in southwest China, providing reference for students' education of rational drug use in colleges and universities.

Methods: A questionnaire survey on knowledge and behavior in rational drug use was carried out on the students recruited by occasional sampling method in 6 colleges and universities in Zunyi, China. Statistical analyses on demographic information and answers to questionnaire questions were carried out with SPSS 18.0.

Results: A total of 865 valid questionnaires were recovered from 923 questionnaires sent out. Some knowledge and behaviors of the students on drug use were irrational. There was statistically significant difference in some specific questions of the knowledge in rational drug use between medical and non-medical students $(P<0.05)$; the average score of rational drug use behavior of medical students was lower than that of non-medical students $(P<0.05)$; the average score of the rational drug use behavior of female students was lower than that of male $(P<0.05)$; the students' major types had significantly different influence on their behavior in rational drug use $(P<0.05)$. The school-carried pharmacy education can effectively improve students' rational medication; the majority of college students believed that it is necessary to popularize the knowledge of rational drug use on campus; and students' favorite way to acquire knowledge about rational drug use was to attend related lectures or elective courses.

Conclusion: The knowledge and behavior of rational drug use among college students need to be improved. Professional medical education may exert a positive impact on rational drug use among college students. Thus, it is necessary to popularize the knowledge of rational drug use among college students, especially in non-medical colleges and universities.

Keywords: college students, rational drug use, knowledge, behavior, ten mistakes in public medication

\section{Introduction}

Medication safety is an important social and livelihood issue. Popularizing knowledge of rational drug use, enhancing public awareness of rational drug use and forming reasonable drug use behavior are of great significance to the promotion of public health. ${ }^{1}$ The "Top Ten Misunderstandings in Public Medication" was summarized from analyzing 816,000 questionnaires collected from the "Drug Safety Network Knowledge Competition" by the Chinese Pharmaceutical Association in 2018, which included the points related to the misunderstandings on knowledge and behavior in medication. ${ }^{1}$

With the rapid development of economy and society and the continuous advancement of medical system reform, people's concept of using medicine is constantly changing. More and more people are willing to choose self-medication, especially in developing countries. ${ }^{2}$ Rational self-medication will bring convenience to patients and save limited healthcare resources; while irrational drug use will not only delay the treatment of diseases, but also lead to adverse drug events and waste of medical resources. ${ }^{3,4}$ According to a WHO survey, one-third of global patients die from 
irrational drug use. ${ }^{5}$ Irrational drug use was listed as the top 10 causes of morbidity and mortality in the United States. ${ }^{6,7}$ In the UK, it costs about $\$ 870$ million to provide nursing and medical treatment for patients who were hospitalized due to adverse medical events. ${ }^{8}$ When it is necessary for a patient to seek help from medical professionals, self-medication by the patient himself will more likely to lead to irrational drug use and result in more potential hazards. ${ }^{9-12}$

College students represent a very important social group closely related to the country's sustainable development. The improvement various abilities and qualities of college students can greatly promote the sustainable development of economy and society. It has been reported that self-medication among students in schools is very popular, and the incidence of self-medication may increase with age. ${ }^{13}$ Some studies have shown that the situation of self-medication is related to the educational level. ${ }^{14,15}$ People who have received high-level education are more inclined to choose selfmedication. The knowledge and behavior of college students on rational drug use should be a topic of great research value in theory and practice. However, there are few researches on the rational medication of college students currently. The public irrational drug use may be contributed to the lack of knowledge and awareness of rational drug use. ${ }^{16}$ In this study, through questionnaire designed on the basis of "Top Ten Mistakes in Public Medication in 2018", we carried out a survey among students in 6 medical and non-medical colleges and universities in Zunyi city and tried to learn about the current situation of college students' knowledge and behavior of rational drug use to provide a useful reference for education and intervention on rational drug use in college students.

\section{Materials and Methods}

All methods were carried out in accordance with relevant guidelines and regulations in this study and all experimental protocols were approved by the Medical Ethics Committee of Zunyi Medical University.

\section{Participant}

This is a descriptive cross-sectional study. Using random sampling method, we selected non-medical students from three non-medical universities or colleges: Zunyi Normal University, Zunyi Vocational and Technical College, and Guizhou Aerospace Vocational and Technical College and medical students from three medical universities or colleges: Zunyi Medical University, Zunyi Medical and Pharmaceutical College and Medicine \& Technology College of Zunyi Medical University. The questionnaire was carried out from November 2019 to January 2020. The undergraduates in these six colleges were included in our study. School staff, postgraduate, and graduate were excluded. We looked after participants mainly in the study rooms of these six universities or colleges, who met the inclusion criteria and agreed to fill out the questionnaire, and invited them to fill out the questionnaire. Verbal informed consent was obtained from all students involved in this study before they filled out the questionnaire.

\section{Investigation Method}

\section{Investigators}

The investigators included a professor and two master students in clinical pharmacy and two pharmacy undergraduate students, who all well understood the objective of the survey and the contents of the questionnaire. After preinvestigation, the investigators summarized and sorted out the problems encountered during the questionnaire survey, and unified the investigation models and methods to deal with problems to ensure the consistency, standardization, reliability, and comparability of the survey results among different universities and colleges.

\section{Questionnaire}

Based on the "Top Ten Misunderstandings in Public Medication", combined with referring to related literatures, we established a self-designed questionnaire mainly including basic demographic information, knowledge of rational drug use and behavior of rational drug use with the Cronbach's $\alpha$ of 0.652 and the KMO of 0.779 . The knowledge and behavior of rational drug use were scored through a 5-point Likert scale with forward questions and reverse questions. In the Basic information section, college students are divided into those from the city and those from the countryside according to the location of the student's home. In addition, the students' opinions on the necessity of rational medication education and their favorite ways to acquire knowledge of rational drug use were also investigated. 
The most of the respondents completed the paper-based questionnaire face-to-face independently. Some of the respondents who are inconvenient to complete it face-to-face were received an electronic version of the questionnaire through mobile phone to complete it independently.

\section{Data Analysis}

SPSS 18.0 was used for statistical analysis of data. The demographic information and the answers to questions about rational drug use were analyzed by descriptive statistics; the differences between two sets of samples on rational medication behavior and knowledge were analyzed by independent sample $t$-test; the correlation between behavior and knowledge of rational drug use was analyzed by Logistic regression; the necessity of education on rational medication and the ways of access to knowledge of rational drug use were evaluated by Chi-square test. The difference was considered as statistically significant with $P<0.05$.

\section{Results}

\section{Basic Information of Respondents}

A total of 923 questionnaires were collected, and 865 valid questionnaires were obtained (There were 578 paper versions and 287 electronic versions) with an effective recovery rate of $93.7 \%$. The questionnaire has basically acceptable reliability and validity with the Cronbach's $\alpha$ of 0.652 and the KMO of 0.779 . The basic demographic information of students includes gender, grade and urban or rural area where they were from. The results (Table 1) show that female students account for $58.4 \%$ of the respondents. The most respondents were freshman $(44.4 \%)$ and from rural areas $(85.7 \%)$.

\section{Analysis on Knowledge in Rational Drug Use}

Among 10 items related knowledge about rational drug use in the questionnaire, questions 2, 3, and 7 were assigned with reverse values, ranging from "extremely disagree" to "extremely agree" with values of 5 to 1 respectively. The rest of the items were assigned from "extremely disagree" to "extremely agree" with 1 to 5 points respectively. A lower score means a better student's cognitive status on rational drug use. Figure 1A and B showed the knowledge in rational drug use of non-medical students and medical students, respectively; Figure 1C showed the average knowledge scores and the difference between two kinds of college students.

\section{Analysis on Behavior in Rational Drug Use}

There were eight items that involved rational drug use behavior in the questionnaire, ranging from "never" to "always" with a value of 1 to 5 respectively. A lower score means a better student's behavior in rational drug use. Figure $2 \mathrm{~A}$ and

Table I Demographic Information

\begin{tabular}{|l|c|c|c|}
\hline Factor & Total (865), n (\%) & Medical (436), n (\%) & Non-Medical (429), n (\%) \\
\hline Gender & & & \\
Male & $360(41.6 \%)$ & $160(36.7 \%)$ & $200(46.6 \%)$ \\
Female & $505(58.4 \%)$ & $276(63.3 \%)$ & $229(53.4 \%)$ \\
College year & $384(44.4 \%)$ & $143(32.8 \%)$ & $241(56.2 \%)$ \\
First & $324(37.5 \%)$ & $186(42.7 \%)$ & $138(32.2 \%)$ \\
Second & $89(10.3 \%)$ & $54(12.4 \%)$ & $35(8.2 \%)$ \\
Third & $55(6.4 \%)$ & $40(9.2 \%)$ & $15(3.5 \%)$ \\
Fourth & $13(1.5 \%)$ & $13(3.0 \%)$ & - \\
Fifth & $123(14.2 \%)$ & $81(18.6 \%)$ & $42(9.8 \%)$ \\
Place of origin & $742(85.8 \%)$ & $355(81.4 \%)$ & $387(90.2 \%)$ \\
Urban & & & \\
Rural & &
\end{tabular}



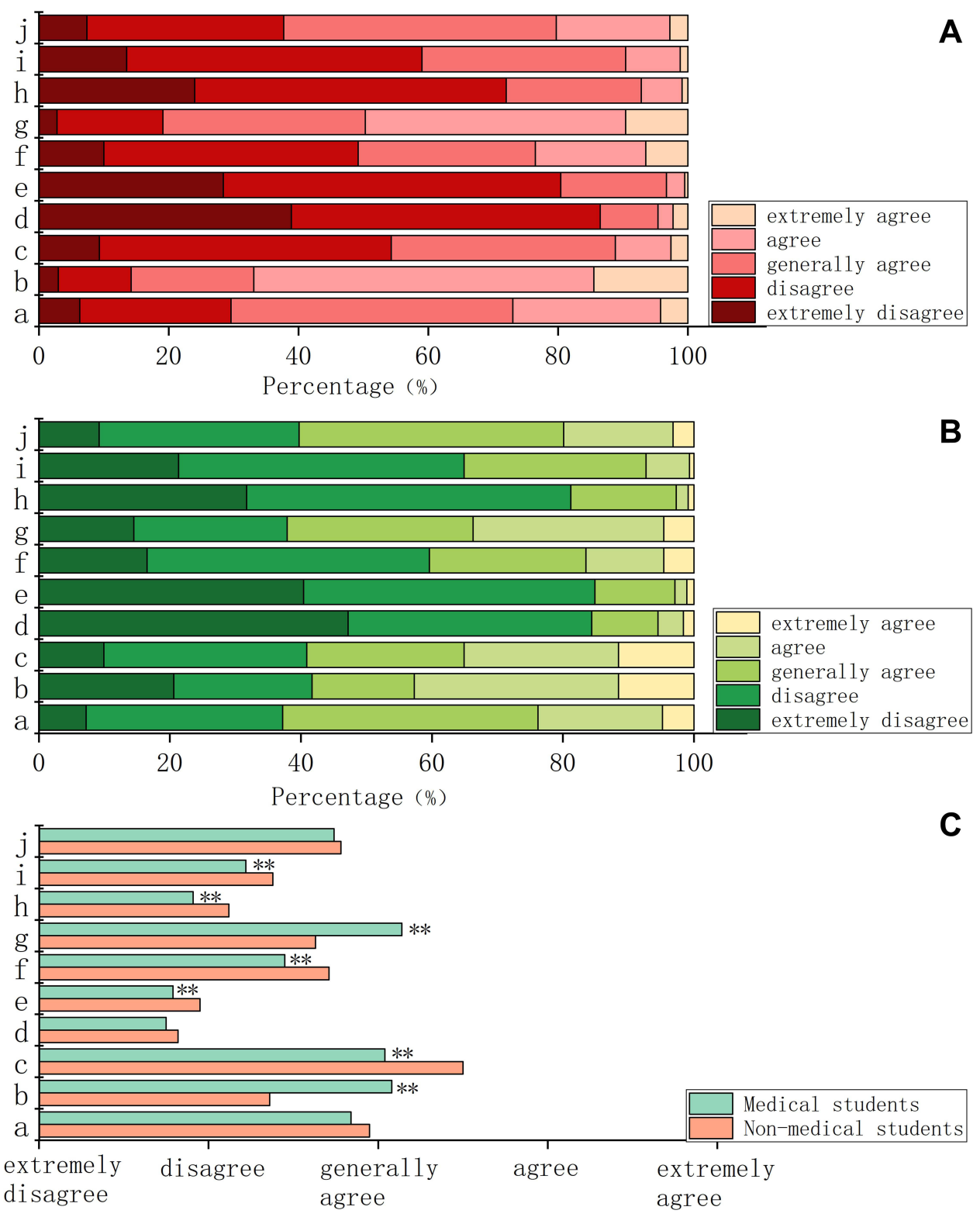

Figure I Knowledge of rational drug use between medical students and non-medical students. (a) The effect of certain drug administered by injection must be better than that by oral administration. (b) Patients can stop taking medication on their own as long as getting better. (c) Drug dependence will occur when insulin is used to treat diabetes. (d) Tea, milk and juice can be used to help swallow medications. (e) I can also take medications that have been used by others to effectively cure their diseases. (f) The medications marked more adverse reactions are less safe. (g) Folk prescription can often be used to treat serious illnesses. (h) Foreign medications purchased online are usually safe and effective. (i) Infusion at the change of the seasons is good for clearing blood vessels. (j) The risk of vaccination is higher than the benefit. (A) non-medical students; (B) medical students; (C) score of knowledge on rational drug use. **Compared with non-medical students, $P<0.0$ I.

B showed the behavior of non-medical students and medical students in rational drug use, respectively; Figure 2C showed the average behavior scores and the difference between two kinds of college students.

\section{Knowledge and Behavior in Rational Drug Use Among Students of Different Genders, Grades and Origins}

Independent sample $t$-test and one-way ANOVA were used to compare the average scores of rational drug use knowledge and behavior of students of different gender, grade, original places and types of majors. The results were shown in Table 2. The difference in the knowledge score and behavior score of different genders in rational medication is statistically significant $(P<0.05)$. Female students' average score of rational drug use knowledge $(2.48)$ and rational 

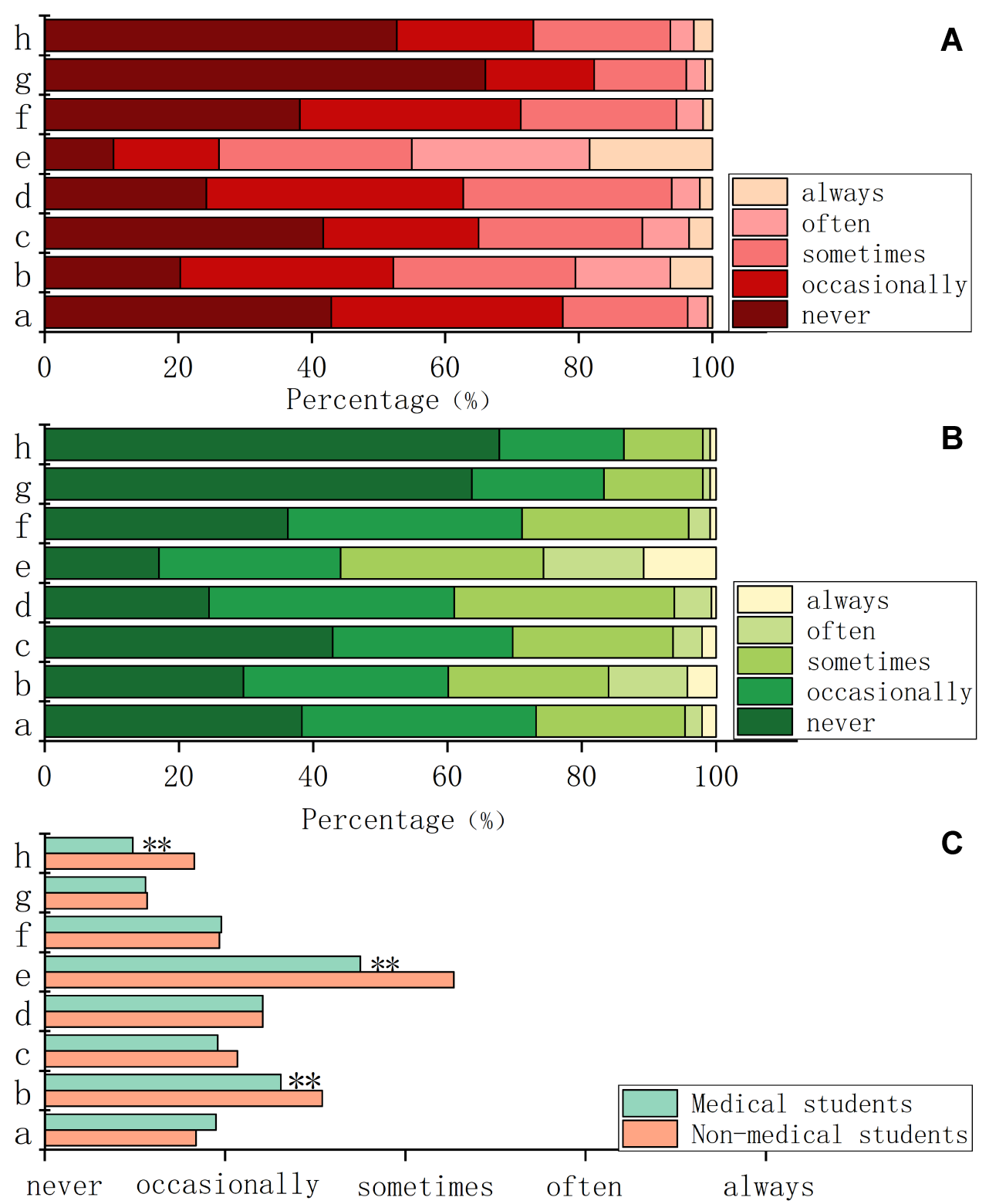

Medical students

Non-medical students

always

Figure 2 Behavior of rational drug use between medical students and non-medical students. (a) Self-assertively increase the type or dose of drugs to improve the therapeutic effect. (b) Stop taking the medicine on my own when getting better. (c) Take the tablets after breaking apart or crushing them. (d) Take medications recommended by friends and relatives. (e) Avoid taking medications for fear of their adverse reactions. (f) Try a folk prescription to treat serious illnesses. (g) Buy foreign medications online when possible. (h) Refuse to get vaccinated for fear of risk. (A) non-medical students; (B) medical students; (C) scores of rational drug use behavior. ***Compared with non-medical students, $P<0.01$.

drug use behavior (2.05) were both lower than those of male students (knowledge: 2.55 and behavior: 2.16), which indicated that female students had better cognitive and behavioral performance than male students in terms of rational drug use. There were no significant differences in knowledge and behavior scores of rational drug use among students of different grades and different places of origin $(P>0.05)$. The difference between medical students and non-medical students in the overall score of rational drug use knowledge was not statistically significant $(P>0.05)$, but the difference between them in the overall score of rational drug use behavior was statistically significant $(P<0.01)$. The average score of rational drug use behavior of medical students (2.03) was lower than that of non-medical students (2.16), which indicated that medical students had better rational drug use behavior than non-medical students. 
Table 2 Knowledge and Behavior of Rational Drug Use Among Students

\begin{tabular}{|l|c|c|c|}
\hline \multicolumn{1}{|l|}{ Factor } & & Knowledge (Mean \pm SD) & Behavior (Mean \pm SD) \\
\hline Gender & Male & $2.55 \pm 0.4$ & $2.16 \pm 0.58$ \\
& Female & $2.48 \pm 0.36$ & $2.05 \pm 0.51$ \\
College year & $\mathrm{P}$ & 0.013 & 0.005 \\
& First & $2.51 \pm 0.33$ & $2.11 \pm 0.54$ \\
& Second & $2.49 \pm 0.38$ & $2.05 \pm 0.49$ \\
& Third & $2.51 \pm 0.46$ & $2.12 \pm 0.63$ \\
& Fourth & $2.58 \pm 0.5$ & $2.23 \pm 0.73$ \\
& Fifth & $2.61 \pm 0.44$ & $2.06 \pm 0.52$ \\
Place of origin & $\mathrm{P}$ & 0.498 & 0.212 \\
& Urban & $2.56 \pm 0.46$ & $2.11 \pm 0.65$ \\
& Rural & $2.5 \pm 0.36$ & $2.09 \pm 0.53$ \\
Types of majors & $\mathrm{P}$ & 0.184 & 0.731 \\
& Medical & $2.5 \pm 0.41$ & $2.03 \pm 0.55$ \\
& Non-medical & $2.52 \pm 0.34$ & $2.16 \pm 0.53$ \\
& $\mathrm{P}$ & 0.379 & 0.000 \\
\hline
\end{tabular}

Table 3 Logistic Regression Analysis of Rational Drug Use Knowledge

\begin{tabular}{|l|c|c|c|c|c|c|}
\hline \multirow{2}{*}{ Factor } & \multicolumn{2}{|c|}{ Non-Standardized Coefficient } & Standardization Coefficient & T & $\mathbf{R}^{\mathbf{2}}$ \\
\cline { 2 - 6 } & $\mathbf{B}$ & $\mathbf{S E}$ & $\boldsymbol{\beta}$ & & \\
\hline Constant & 2.072 & 0.098 & - & 21.058 & 0.000 \\
Gender & -0.036 & 0.024 & -0.047 & -1.487 & 0.138 & 0.164 \\
College year & 0.009 & 0.013 & 0.023 & 0.716 & 0.474 \\
Place of origin & -0.043 & 0.034 & -0.04 & -1.252 & 0.211 \\
Type of majors & -0.01 & 0.025 & -0.013 & -0.404 & 0.686 & \\
\hline
\end{tabular}

Table 4 Logistic Regression Analysis of Rational Drug Use Behavior

\begin{tabular}{|l|c|c|c|c|c|c|}
\hline \multirow{2}{*}{ Factor } & \multicolumn{2}{|c|}{ Non-Standardized Coefficient } & $\begin{array}{c}\text { Standardization } \\
\text { Coefficient }\end{array}$ & T & $\mathbf{R}^{2}$ \\
\cline { 2 - 6 } & B & SE & $\boldsymbol{\beta}$ & & \\
\hline Constant & 0.53 & 0.174 & 0.39 & 12.504 & 0.002 \\
Knowledge & 0.565 & 0.045 & -0.051 & -1.621 & 0.000 \\
score & -0.056 & 0.035 & 0.036 & 1.129 & 0.259 \\
Gender & 0.021 & 0.019 & 0.002 & 0.061 & 0.951 \\
College year & 0.003 & 0.049 & 0.117 & 3.618 & 0.000 \\
Place of origin & 0.128 & 0.035 & & & \\
Type of majors & & & & \\
\hline
\end{tabular}

\section{Logistic Regression Analysis on Knowledge and Behavior in Rational Drug Use}

Logistic regression analysis was performed on each factor and the average scores of all students' rational drug use knowledge and rational drug use behavior. The result was shown in Tables 3 and 4. From Table 3, we can see that impact of gender, grade, original places and types of majors on rational drug use knowledge are all not statistically significant $(P>0.05)$, which indicates that college students' rational drug use knowledge in different situation all need to be improved. From Table 4, we can see that standardization coefficient of rational drug use knowledge on rational drug use among college students is positive $(\beta>0, P<0.01)$, which indicates that college students' rational drug use knowledge has a significant positive impact on their behavior in rational drug use. Also, the standardization coefficient of college 
Table 5 The Students' Opinion on Necessity and Favorite Way of Rational Drug Use Education

\begin{tabular}{|c|c|c|c|c|}
\hline & $\begin{array}{l}\text { Medical, } \\
\text { n (\%) }\end{array}$ & $\begin{array}{l}\text { Non-Medical, } \\
\text { n (\%) }\end{array}$ & $\chi^{2}$ & $\mathbf{P}$ \\
\hline $\begin{array}{l}\text { Do you think it is necessary to popularize the knowledge of rational drug use on } \\
\text { campus? }\end{array}$ & & & 9.029 & 0.06 \\
\hline Completely unnecessary & $8(1.8 \%)$ & $8(1.9 \%)$ & & \\
\hline Not necessary & $5(1.1 \%)$ & $2(0.5 \%)$ & & \\
\hline It depends & $32(7.3 \%)$ & $44(10.3 \%)$ & & \\
\hline Necessary & $170(39.0 \%)$ & 195 (45.5\%) & & \\
\hline Completely necessary & $22 ।(50.7 \%)$ & $180(42.0 \%)$ & & \\
\hline The most favorite way for you to obtain the knowledge of rational drug use & & & 37.192 & 0.000 \\
\hline Questionnaire investigation and knowledge competition & $4 \mathrm{l}(9.4 \%)$ & $90(21.0 \%)$ & & \\
\hline Television and radio publicity & $98(22.5 \%)$ & $99(23.1 \%)$ & & \\
\hline Internet media & $83(19.0 \%)$ & 68 (15.9\%) & & \\
\hline Brochures, posters & $36(8.3 \%)$ & $56(13.1 \%)$ & & \\
\hline Lectures and elective courses & 178 (40.8\%) & $116(27.0 \%)$ & & \\
\hline
\end{tabular}

students' major types (medical or non-medicine) on rational drug use behavior is positive $(\beta>0, P<0.01$ ), which indicates that medical and non-medical college students have significantly different performance on their behavior in rational drug use.

\section{Students' Opinion on Necessity and Ways of Education in Rational Drug Use}

As can be seen from Table 5, for the topic of "Do you think it is necessary to popularize the knowledge of rational drug use on campus", there was no significant difference between the knowledge of medical students and non-medical students $(P>0.05)$. Most students believed it is necessary to popularize the knowledge of rational drug use on campus. In view of favorite ways to obtain knowledge about rational drug use, there was statistically significant difference between the two types of students $(P<0.01)$. The top three most desirable ways for medical students to receive education on rational drug use were "knowledge lectures and elective courses", "television and radio publicity" and "internet media". By contrast, the top three most desirable ways for non-medical students were "knowledge lectures and elective courses", "television and radio publicity" and "questionnaire investigation and knowledge competition". All the students believed that it is the best to acquire knowledge of rational drug use through "knowledge lectures and elective courses".

\section{Discussion}

According to our results, quite a number of students had irrational knowledge and behavior of drug use, such as most of the medical students $(62.8 \%)$ and the non-medical students (70.4\%) in this survey considered that the effect of certain drug administered by injection must be better than that by oral administration; a considerable number of medical students (41.7\%) believed that patients can stop taking medication on their own when they feel getting better; more than half of non-medical students $(54.3 \%)$ believed that drug dependence will occur when insulin is used to treat diabetes; some nonmedical students $(50.8 \%)$ thought that the medications marked more adverse reactions are less safe; some medical students (37.9\%) thought that folk prescriptions can often be used to treat serious illnesses; some non-medical students (41\%) believed that infusion at the change of the seasons is good for clearing blood vessels; some medical students (40\%) and non-medical students (47.8\%) may stop taking medicines by themselves when their condition improved; and most non-medical students (73.9\%) sometimes or often avoid using drugs for fear of drug adverse reactions. Therefore, education on rational drug use for college students needs to be strengthened urgently. Deo et al conducted a questionnaire survey about knowledge of use of antibiotic on students in private schools and also found that almost all of the participating students lacked adequate knowledge regarding antibiotics and that student need to upgrade their knowledge on the safe use of antibiotics. ${ }^{17}$ 
Our results showed that female students had better behavior and knowledge about rational drug use than male students, which may be due to the fact that female students are more careful and pay more attention to details about their health than male students. This is similar with Hidayah Karuniawati's results from self-designed questionnaire found that men are more prone to excessive use of antibiotics. ${ }^{18}$ Though the knowledge scores of non-medical students were better than those of medical students in two items among the questions about the knowledge of rational drug use and medical students showed better knowledge than non-medical students in five items, there was no significant difference between medical students and non-medical students in the overall knowledge of rational drug use $(\mathrm{P}>0.05)$. This result is different from our previous prediction that medical students should have a better overall understanding of rational drug use than non-medical students. This may be attributed to the rapid development of network information in recent years and the increasingly important role of network for the public to obtain medical knowledge. ${ }^{19}$ As we anticipated, medical students had a higher average score than non-medical students in the rational drug use behavior; and the logistic regression analysis of rational drug use behavior also showed that the type of majors (medical or non-medical) of the students had a significant impact on the rational drug use behavior. The professional medical education may make medical students know more about the harm caused by irrational drug use, and thus use drugs in more professional manners. School education may be the basic way to improve rational drug use behavior of college students. Similar research found that a significant gap in the level of knowledge/attitude/practice of antibiotic use between the medical student and nonmedical student. ${ }^{20}$

The results showed that grade and places of origin had no statistically significant influence on college students' knowledge and behavior of rational drug use. This is different with a previous study carried out in China shown that grade had an influence on college students' behavior of rational drug use and Poonam Shah's study shown that a significant gap in the level of knowledge/attitude/practice of antibiotic use between the first- and last-year study students. ${ }^{20,21}$ This may be partially explained by the fact that the promotion of popularization of medical science in China in recent years has effectively improved the medical and health literacy of all citizens, including middle school and university students both in urban and rural areas. There may be many factors that affect college students' knowledge and behavior in rational drug use, and further research will be needed to prove more influencing factors. Although some studies have shown that students' knowledge and behavior of rational drug use need to be improved, ${ }^{22}$ there are few studies to investigate the difference between medical students and non-medical students about rational drug use, the students' views on the necessity and their favorite way of education in rational drug use. We report the difference in knowledge and behavior of rational drug use between medical students and non-medical students and the students' views on the necessity and their preferred modes of education in rational drug use. The results suggested that the schools' medical education may exert a positive impact on behavior in rational drug use among college students, and that the proper knowledge in rational drug use can positively influence the behavior of rational drug use. Most students believed that it is necessary to popularize the knowledge of rational drug use in schools. The non-medical students prefer to acquire knowledge of rational drug use through "questionnaire investigation and knowledge competition", while the medical students prefer through "knowledge lectures and elective courses". This may be due to the fact that non-medical students rarely receive professional medical knowledge education and will prefer to "questionnaire investigation and knowledge competition" as a more participatory educational method. In general, the number of students who prefer to acquire knowledge related to rational drug use through knowledge lectures and elective courses accounts for the largest proportion.

College students usually lack life experience, and non-medical college students especially lack basic professional knowledge related to rational drug use, which may lead to irrational drug use and health risks in their self-diagnosis and self-medication. ${ }^{23-27}$ Self-medication behavior in college students is relatively common and exceeds the average level in general social population, especially the self-medication rate of non-medical college students seems higher than that of medical college students. ${ }^{28-32}$ This will lead to a greater potential of safety hazard for college students. Though it is convenient to acquire knowledge through internet media, Chinese college students rely too heavily on online health information to manage their own and others' health without sufficient knowledge and skills to identify misinformation and disinformation, thereby placing themselves and others at health risk. ${ }^{33}$ Education is the most important way in changing behavior, and tailor-made education will effectively improve personal awareness and skills. ${ }^{34}$ Elective courses, 
as a platform for educational practice, can create opportunities for students to explore interests in a certain field, expand their knowledge field, and deepen their understanding of a particular subject area. ${ }^{35-37}$ Therefore, educators in universities and colleges can develop elective courses to improve students' knowledge and behavior on rational drug use by popularizing relevant knowledge on rational drug use. Through the mutual influence between proper knowledge and standardized behavior on rational drug use in college students, they can safely and reasonably use drugs during selfmedication and reduce the incidence of adverse medication events. At the same time, as college students enter society after graduation, their consciousness and behavior in rational drug use will also affect other members of society and their descendants, making them use drugs more reasonably and safely.

This study had some deficiencies. The college students in this study were included by random sampling, which may lead to some deviations; the influencing factors of knowledge and behavior in rational drug use among college students were not quantitatively analyzed. Therefore, further research should be carried out with more standardized design to clarify relevant factors and provide systematic intervention suggestions for improving knowledge and behavior in rational drug use among college students.

\section{Conclusion}

The knowledge and behavior of college students on rational drug use need to be improved. Although there is no statistically significant difference between medical students and non-medical students in knowledge of rational drug use, non-medical students do not perform as well as medical students in rational drug use behavior. Professional medical education will have a positive impact on the rational drug use among college students. It is necessary and beneficial to popularize the knowledge of rational drug use in colleges and universities, especially non-medical colleges and universities. The most desirable way for most students to gain knowledge of rational drug use is to participate in knowledge lectures or elective courses related to rational drug use. Schools, families and society should pay sufficient attention to the medication safety of college students, and guide and adjust their drug use behavior in a timely and targeted manner.

\section{Ethics Approval and Consent to Participate}

The study was approved by the Medical Ethics Committee of Zunyi Medical University (ZMUER [2021]1-029), and conducted in accordance with the Declaration of Helsinki. The informed consent process was approved by the ethics committee. Verbal informed consent from all participants was obtained face to face at the survey sites, and electronically from online participants. Through the explanation letter at the front of the questionnaire and the explanation work at the investigation site, all the college students involved in the investigation clearly understood the purpose of the study. Participation to the study was voluntary and anonymous.

\section{Acknowledgments}

The survey was supported partly by the Key Laboratory of Clinical Pharmacy in Zunyi City of the Zunyi Medical University. The authors gratefully thank all college students, who completed the questionnaire voluntarily and actively. The helpful discussions with Miss Cheryl Roberts in Gansu Normal College for Nationalities and Dr. Zhijun Liu in Zunyi Medical University are specially appreciated by the authors.

\section{Disclosure}

The authors report no conflicts of interest in this work.

\section{References}

1. The Editorial office of Chinese Pharmaceutical Journal. The Chinese Pharmaceutical Association released the "Ten mistakes in public medication in 2018". Chin Pharmacol J. 2018;53(21):1868.

2. Shehnaz SI, Agarwal AK, Khan N. A systematic review of self-medication practices among adolescents. J Adolesc Health. 2014;55(4):467-483. doi:10.1016/j.jadohealth.2014.07.001

3. Tian LJ, Yu PM. Discuss on the irrational drug use and the countermeasures in China. Chin Pharm. 2005;16(16):1204-1206. 
4. Rehman M, Ahmed S, Ahmed U, et al. An overview of self-medication: a major cause of antibiotic resistance and a threat to global public health. J Pak Med Assoc. 2021;71(3):943-949. doi:10.47391/JPMA.1331

5. Surmelioglu N, Kiroglu O, Erdogdu T, et al. Measures for prevention of irrational drug use. Arch Med Rev J. 2015;24(4):452-462.

6. White TJ, Arakelian A, Rho JP. Counting the costs of drug-related adverse events. Pharmacoeconomics. 1999;15(5):445-458. doi:10.2165/ 00019053-199915050-00003

7. Lazarou J, Pomeranz BH, Corey PN. Incidence of adverse drug reactions in hospitalized patients: a meta-analysis of prospective studies. JAMA. 1998;279(15):1200-1205. doi:10.1001/jama.279.15.1200

8. Mao W, Vu H, Xie Z, et al. Systematic review on irrational use of medicines in China and Vietnam. PLoS One. 2015;10(3):e0117710. doi:10.1371/ journal.pone. 0117710

9. Panda A, Pradhan S, Mohapatra G, et al. Drug-related problems associated with self-medication and medication guided by prescription: a pharmacy-based survey. Indian J Pharmacol. 2016;48(5):515-521. doi:10.4103/0253-7613.190728

10. Fainzang S. Managing medicinal risks in self-medication. Drug Saf. 2014;37(5):333-342. doi:10.1007/s40264-014-0153-z

11. Zafar SN, Syed R, Waqar S, et al. Self-medication amongst university students of Karachi: prevalence, knowledge and attitudes. J Pak Med Assoc. 2008;58(4):214-217.

12. Alshogran OY, Alzoubi KH, Khabour OF, et al. Patterns of self-medication among medical and nonmedical university students in Jordan. Risk Manag Healthc Policy. 2018;11:169-176. doi:10.2147/RMHP.S170181

13. ALBashtawy M, Batiha AM, Tawalbeh L, et al. Self-medication among school students. J Sch Nurs. 2015;31(2):110-116. doi:10.1177/ 1059840514554837

14. Kifle ZD, Mekuria AB, Anteneh DA, et al. Self-medication practice and associated factors among private health sciences students in Gondar town, North West Ethiopia. A cross-sectional study. Inquiry. 2021;58:469580211005188. doi:10.1177/00469580211005188

15. Garofalo L, Di Giuseppe G, Angelillo IF. Self-medication practices among parents in Italy. Biomed Res Int. 2015;2015:580650. doi:10.1155/2015/ 580650

16. Soleymani F, Ahmadizar F, Meysamie A, et al. A survey on the factors influencing the pattern of medicine's use: concerns on irrational use of drugs. J Res Pharm Pract. 2013;2(2):59-63. doi:10.4103/2279-042X.117385

17. Deo SK, Rijal S, Kunwar SD, et al. Knowledge of use of antibiotic, its resistance and consequences among students in private schools. $J$ Nepal Med Assoc. 2018;56(212):740-744. doi:10.31729/jnma.3672

18. Karuniawati H, Hassali MAA, Suryawati S, et al. Assessment of knowledge, attitude, and practice of antibiotic use among the population of Boyolali, Indonesia: a cross-sectional study. Int J Environ Res Public Health. 2021;18(16):8258. doi:10.3390/ijerph18168258

19. Zhang SH, Wang J, Dong YF, et al. Cross-cultural communication of traditional Chinese medicine in the Internet era. Lishizhen Med Mater Med Res. 2017;28(5):1277-1280.

20. Shah P, Shrestha R, Mao Z, et al. Knowledge, attitude, and practice associated with antibiotic use among university students: a survey in Nepal. Int J Environ Res Public Health. 2019;16(20):3996. doi:10.3390/ijerph16203996

21. Liu SC, Shen LJ. Study on the rational drug use status and influencing factors of college students in Hangzhou. J Mod Med Health. 2018;34 (12):1776-1780.

22. He X, Yang JT, Wang WH, et al. Investigation on knowledge, attitude and behavior of rational drug use among medical college students. Health Voc Educ. 2010;28(8):113-114.

23. Hughes CM, McElnay JC, Fleming GF. Benefits and risks of self-medication. Drug Saf. 2001;24(14):1027-1037. doi:10.2165/00002018200124140-00002

24. Shen ZY, Ding SQ, Zhong ZQ, et al. Analysis and countermeasures of self-medication behavior and problems in medication safety. $J$ Nurs Sci. 2016;1(6):105-108.

25. Li WN, Zeng Y, Huang ZL. Investigation and analysis on the self-medication behavior of college students. Chin Pharm Affair. 2016;30 (12):1264-1269.

26. Xiao YD. Investigation and analysis on the current situation of self-medication of college students. J Taiyuan Urban Voc Coll. 2012;6:116-117.

27. Li X, Qin JX, Wang YA, et al. Investigation and analysis of medication knowledge and behavior of undergraduates in 9 non-medical colleges in Beijing. Chin Pharm. 2018;29(8):1131-1135.

28. Sawalha AF. A descriptive study of self-medication practices among Palestinian medical and nonmedical university students. Res Social Adm Pharm. 2008;4(2):164-172. doi:10.1016/j.sapharm.2007.04.004

29. Klemenc-Ketis Z, Hladnik Z, Kersnik J. Self-medication among healthcare and non-healthcare students at University of Ljubljana, Slovenia. Med Princ Pract. 2010;19(5):395-401. doi:10.1159/000316380

30. Niroomand N, Bayati M, Seif M, et al. Self-medication pattern and prevalence among Iranian medical sciences students. Curr Drug Saf. 2020;15 (1):45-52. doi:10.2174/1574886314666191022095058

31. Akande-Sholabi W, Ajamu AT, Adisa R. Prevalence, knowledge and perception of self-medication practice among undergraduate healthcare students. J Pharm Policy Pract. 2021;14(1):49. doi:10.1186/s40545-021-00331-w

32. Chakravarthy SA, Maiya GR. Prevalence of self-medication and its associated factors among students of an engineering college in Chennai. J Family Med Prim Care. 2021;10(3):1204-1208. doi:10.4103/jfmpc.jfmpc_1654_20

33. Zhang D, Zhan W, Zheng C, et al. Online health information-seeking behaviors and skills of Chinese college students. BMC Public Health. 2021;21 (1):736. doi:10.1186/s12889-021-10801-0

34. Arlinghaus KR, Johnston CA. Advocating for behavior change with education. Am J Lifestyle Med. 2017;12(2):113-116. doi:10.1177/ 1559827617745479

35. Steuber TD, Janzen KM, Walton AM, et al. Assessment of learner metacognition in a professional pharmacy elective course. Am J Pharm Educ. 2017;81(10):6034. doi:10.5688/ajpe6034

36. Arif S, Wang S, Lakada IY, et al. An elective course to train student pharmacists to provide culturally sensitive health care. Am J Pharm Educ. 2019;83(8):7027. doi:10.5688/ajpe7027

37. Bose DD. An elective course in cardiovascular electrophysiology for pharmacy learners. Am J Pharm Educ. 2016;80(8):130. doi:10.5688/ ajpe 808130 


\section{Publish your work in this journal}

Risk Management and Healthcare Policy is an international, peer-reviewed, open access journal focusing on all aspects of public health, policy, and preventative measures to promote good health and improve morbidity and mortality in the population. The journal welcomes submitted papers covering original research, basic science, clinical \& epidemiological studies, reviews and evaluations, guidelines, expert opinion and commentary, case reports and extended reports. The manuscript management system is completely online and includes a very quick and fair peer-review system, which is all easy to use. Visit http://www.dovepress.com/testimonials.php to read real quotes from published authors.

Submit your manuscript here: https://www.dovepress.com/risk-management-and-healthcare-policy-journal 